University of Nebraska - Lincoln

DigitalCommons@University of Nebraska - Lincoln

Educational Psychology Papers and

Publications

Educational Psychology, Department of

1989

\title{
The Influence of Parental Attitude and Behavior on Early Adolescent Cigarette Smoking
}

Ian Newman

University of Nebraska-Lincoln, inewman1@unl.edu

Jolene M. Ward

Deaconess Hospital, St. Louis, MO

Follow this and additional works at: https://digitalcommons.unl.edu/edpsychpapers

Part of the Educational Psychology Commons

Newman, lan and Ward, Jolene M., "The Influence of Parental Attitude and Behavior on Early Adolescent Cigarette Smoking" (1989). Educational Psychology Papers and Publications. 98.

https://digitalcommons.unl.edu/edpsychpapers/98

This Article is brought to you for free and open access by the Educational Psychology, Department of at DigitalCommons@University of Nebraska - Lincoln. It has been accepted for inclusion in Educational Psychology Papers and Publications by an authorized administrator of DigitalCommons@University of Nebraska - Lincoln. 


\title{
The Influence of Parental Attitude and Behavior on Early Adolescent Cigarette Smoking
}

\author{
Ian M. Newman, PhD, FASHA, Professor, Health Education and Director, Nebraska Prevention Center \\ for Alcohol and Drug Abuse, 225 Coliseum, University of Nebraska-Lincoln, Lincoln, NE 68588-0138
}

Jolene M. Ward, MEd, RN, Staff Nurse, Deaconess Hospital, 6150 Oakland, St. Louis, MO 63139

\begin{abstract}
In 1983, Nolte and colleagues reported parental attitude may be more powerful than parental behavior in shaping adolescent cigarette smoking behavior. This study replicates the finding of Nolte et al. and suggests parents need to be actively recruited to discourage their children from smoking, regardless of their own behavior. Fewer parents actively discourage youth smoking today than in 1983, a possible unfortunate result from on apparently successful effort to change the public attitude toward cigarette smoking.
\end{abstract}

Parental smoking behavior and its relationship to adolescent cigarette smoking behavior has been studied extensively. The effect of parental attitude on adolescent smoking, however, has received less attention, and the effect of the combination of parental attitude and behavior largely has been ignored. One notable exception was the study by Nolte and colleagues. ${ }^{1}$ They concluded that while parental attitude and behavior affected adolescent smoking behavior, the joint effects were much more powerful than previously noticed, and that attitude may be the more powerful of the two.

Smoking habits established in adolescence tend to prevail into later years. Kandel and Logan ${ }^{2}$ suggested cigarette usage rates for both male and female adolescents increase at age 12 and rise consistently through age 18 . Thus, understanding patterns of initiation and identification of factors related to initiation become important to those interested in reducing the rate at which young people begin the smoking habit.

Basing parental smoking behavior on the reports of their children and inferring parental attitude from adolescents' reports on how upset parents were or would be if they smoked, Nolte et al. ${ }^{1}$ reported that when both parents smoked and were not upset if their adolescents smoked, $51.6 \%$ of their adolescents smoked. When smoking parents were upset if their adolescents smoked, only $10.4 \%$ of their adolescents reported smoking. For nonsmoking parents who were upset at the prospect of their children smoking, only $5.3 \%$ of their children reported smoking. When nonsmoking parents did not object to their children smoking, $23.3 \%$ reported smoking (Table 1).

If parents' attitudes toward smoking exert such an effect on subsequent smoking patterns of their adolescents, then health educators need to design strategies to encourage parents to express their nonaccepting attitudes.
This paper reports a replication of findings from Nolte et al. ${ }^{1}$ with data from students in grades seven and eight from a different population. The sample described in this paper included 735 students from 12 schools in and around one moderately sized midwestern city who were significantly younger than those in Nolte's sample: students ages 13-14 compared to Nolte's 5,411 students in grades 7-12.

Definitions also differed slightly from those used by Nolte et al. Students were classified as smokers if they had smoked more than two cigarettes. Measures of parental attitude were derived from a question asking, "With regards to my smoking cigarettes, my parents/guardian would: threaten to punish me if I smoked; have told me never to smoke; haven't told me how they feel if I smoke; have told me they don't care if I smoke." Nolte and colleagues explored the influence of individual parents. Due to the smaller sample, this study only explored the effect of "both" parents disapproving. One parent approving and one disapproved was classified as indifferent.

\section{Findings}

Almost one-half $(49.8 \%)$ the students in this sample reported neither parent smoked; $15.4 \%$ reported both parents smoked. When only one parent smoked, it was more likely to be the father $(21.2 \%)$ than the mother $(13.5 \%)$ (Table 2).

Parental Behavior. In this sample, $18.5 \%$ of adolescents were "smokers." Among the adolescents who were nonsmokers. $46.8 \%$ reported one or more parent smoked. Among the "smokers" $66.2 \%$ reported smoking by one or more parents $\left(x^{2}+p<.004\right)$.

Parental Attitudes. Almost two-thirds of the students $(65.8 \%)$ reported both parents would be upset and would disapprove if they smoked (threatened to punish them, 
Table I. Youth Smoking Behavior by Parental Attitudes and Parental Behaviors (Modified from Nolte et al., 1983)

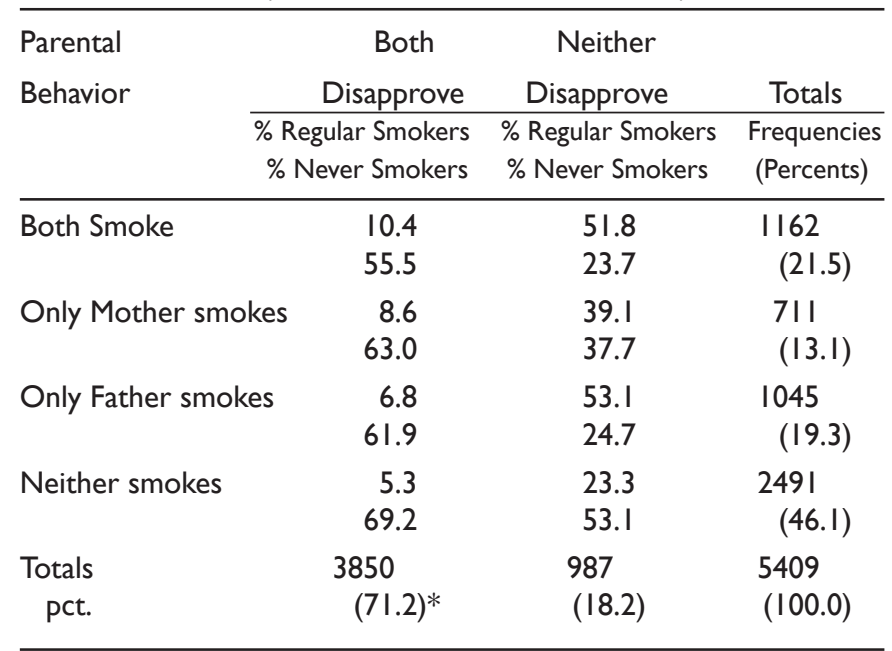

* Parental disapproval percentages do not equal 100\% because cases where one parent disapproved and one was indifferent (mixed attitude) are omitted.

or told them never to smoke). No significant difference existed in attitudes of parents of males or females. Two-thirds $(67.9 \%)$ of nonsmokers and $55.6 \%$ of smokers reported their parents were or would be upset with their smoking. Adolescent cigarette smoking in this sample was related to parental attitude expressed as disapproval $\left(x^{2}=6.82, p<.009\right)$.

Parental Attitude and Behavior. The data in Table 2 shows that when neither parent smoked and both disapproved of their adolescents smoking, 10.3\% of their adolescents smoked. Holding attitude constant, both parents having a negative attitude toward their adolescent smoking, but with both parents as smokers, the percentage of smoking adolescents increased to $18.8 \%$. When neither parent smoked and parents were indifferent toward their adolescent smoking, $17.8 \%$ of their adolescents smoked. Again, holding attitude constant, parents indifferent, but with both parents as smokers, the number of smoking adolescents increased to $32.5 \%$.

\section{Discussion}

Nolte and colleagues observed a twofold difference in the proportion of adolescent smokers and nonsmokers when both parents smoked compared to nonsmoking parents $(21.9 \%-46.1 \%)$. This study showed a threefold difference in the proportion of smokers when both parents smoked compared to when neither parent smoked (15.4\% - 49.8\%).

Nolte et al. reported a fivefold difference in the proportion of smoking adolescents when smoking parents disapproved of adolescent smoking compared to when they were indifferent $(10.4 \%-51.6 \%)$. These data suggest a twofold difference of $18.8 \%-32.5 \%$. Similarly, Nolte et al. noted that nonsmoking parents who disapproved of smoking were less likely to have smoking adolescents than indifferent nonsmoking parents $(5.3 \%-23.3 \%)$. This study suggested a smaller difference; smoking parents who disapproved had $10.3 \%$ smoking adolescents compared to indifferent smoking parents who had $17.8 \%$ smoking adolescents.
Table 2. Youth Smoking Behavior by Parental Attitudes and Parental Behaviors (this study)

\begin{tabular}{|c|c|c|c|}
\hline \multirow[t]{2}{*}{$\begin{array}{l}\text { Parental } \\
\text { Behavior }\end{array}$} & $\begin{array}{c}\text { Both } \\
\text { Disapprove }\end{array}$ & \multicolumn{2}{|l|}{$\begin{array}{l}\text { Parents } \\
\text { Indifferent }\end{array}$} \\
\hline & $\begin{array}{l}\text { \% Regular Smokers } \\
\text { \% Never Smokers }\end{array}$ & $\begin{array}{l}\text { \% Regular Smokers } \\
\% \text { Never Smokers }\end{array}$ & $\begin{array}{r}\text { Frequencies } \\
\text { (Percents) }\end{array}$ \\
\hline Both Smoke & $\begin{array}{l}18.8 \\
81.3\end{array}$ & $\begin{array}{l}32.5 \\
67.5\end{array}$ & $\begin{array}{l}104 \\
(15.4)\end{array}$ \\
\hline Only Mother smoke & $\begin{array}{l}19.2 \\
80.8\end{array}$ & $\begin{array}{l}18.4 \\
81.6\end{array}$ & $\begin{array}{l}90 \\
(13.5)\end{array}$ \\
\hline Only Father smokes & $\begin{array}{l}25.0 \\
75.0\end{array}$ & $\begin{array}{l}32.0 \\
68.0\end{array}$ & $\begin{array}{l}142 \\
(21.2)\end{array}$ \\
\hline Neither smokes & $\begin{array}{l}10.3 \\
89.7\end{array}$ & $\begin{array}{l}17.8 \\
82.2\end{array}$ & $\begin{array}{l}333 \\
(49.8)\end{array}$ \\
\hline $\begin{array}{l}\text { Totals } \\
\text { pct. }\end{array}$ & $\begin{array}{l}440 \\
(65.8)\end{array}$ & $\begin{array}{l}229 \\
(34.2)\end{array}$ & $\begin{array}{l}669 \\
(100.0)\end{array}$ \\
\hline
\end{tabular}

Nolte et al. reported a tenfold synergistic relationship between parental attitude and behavior in adolescent smoking. When both parents disapproved and did not smoke, $5.3 \%$ of their adolescents smoked. When both parents were indifferent and smoked, $51.6 \%$ of their adolescents smoked. These results are similar but in the magnitude of a threefold difference. Nonsmoking parents who disapproved had $10.3 \%$ of their adolescents smoking, while smokers who were indifferent had $32.5 \%$ of their youngsters smoking.

While the magnitude of differences in this study generally were less than differences reported by Nolte et al., the direction and magnitude of these differences still were significant. These results replicate the 1983 results reported by Nolte and colleagues.

One result of concern from this study involves the apparent increase in permissiveness of parents toward their adolescents smoking. As students in this study were junior high school rather than junior and senior high school students on which Nolte et al. based their results, it was anticipated that a greater degree of parental disapproval of cigarette smoking would be expressed to these younger adolescents. This result was not found. Nolte et al indicated $18.2 \%$ of their sample reported that both parents were not upset or were indifferent in their attitudes toward their adolescents cigarette smoking. These data show $34.2 \%$ of the sample reporting parents as indifferent. The more accepting attitude of parents represents one possible reason why the magnitude of differences between behavior and attitude reported here were less than Nolte et al observed. Parental attitude may not be as salient to adolescents today as in 1983.

\section{Conclusion}

From an educational perspective, these results and the findings of Nolte et al. suggest two important points. Parental attitude, when expressed, appears to be important in moderating adolescent smoking behavior regardless of parents smoking behavior. Many parents suggest they are un- 
able to tell their youngsters not to smoke when they smoke because of the apparent hypocrisy. Clearly, these two studies suggest parents' expressed opposition does affect smoking behavior, regardless of actual parental behavior. Parents should he encouraged to clearly express their opposition to risky behaviors such as cigarette smoking.

The second point involves the apparent increase in permissiveness of parents. Today, even more than in 1983, the dangers of cigarettes are documented by the scientific community, and accepted by parents and community members. Why are more parents indifferent in their attitudes toward their adolescents smoking? Perhaps the very changes in public attitude, accepting the dangers of smoking and establishment of policies that discourage smoking, led parents to feel the antismoking message is clear and they no longer need to state the obvious to their youngsters.

Fishbein and Ajzen ${ }^{3}$ pointed out that a generic message such as "smoking is bad for health" proves less effective at influencing a behavior than a specific and personal message such as "MY smoking is bad for MY health." The increasing acceptance of a generic message may be decreasing the number of more effective personal messages, and hence the effectiveness of the message may be decreased.
This study suggests school personnel can recruit an effective ally - parents - in their efforts to decrease the rate of adolescent cigarette smoking. These data suggest parents should be encouraged to express their objection to youth smoking in increasing numbers and to do so regardless of their own smoking behavior.

\section{References}

1. Nolte, A. E., Smith, B. J., O'Rourke, T. The relative importance of parental attitudes and behavior upon youth smoking behavior. J Sch Health 1983; 53(4):261-271.

2. Kandel, D. B., Logan, J. A. Patterns of drug use from adolescent to young adulthood: I. Periods of risk for initiation, continued use and discontinuation. Am J Public Health 1984; 74(7):660-665.

3. Fishbein, M., Ajzen, I. Belief, Attitude, Intention and Behavior: An Introduction to Theory and Practice. Reading, MA: Addison-Wesley, 1975, pp. 216-284. 